\section{Case Reports in Neurology}

Case Rep Neurol 2021;13:246-250

DOI: 10.1159/000511428

Published online: April 19, 2021
(C) 2021 The Author(s)

Published by S. Karger AG, Basel www.karger.com/crn

This article is licensed under the Creative Commons Attribution-NonCommercial 4.0 International License (CC BY-NC) (http://www.karger.com/Services/OpenAccessLicense). Usage and distribution for commercial purposes requires written permission.

\title{
Headache due to Bilateral Subacute Subdural Hematomas following Intracranial Hypotension Caused by Cervical Disc Herniation
}

\author{
Iris Steenstraten ${ }^{a} \quad$ Stephanie Mohamed ${ }^{a} \quad$ Hille Koppen $^{a, b}$ \\ aDepartment of Neurology, Haga Hospital, The Hague, The Netherlands; ${ }^{b}$ Department of \\ Neurology, Leiden University Medical Center, Leiden, The Netherlands
}

\section{Keywords}

Spontaneous intracranial hypotension · Disc herniation · Cerebrospinal fluid · Orthostatic headache

\begin{abstract}
Spontaneous intracranial hypotension $(\mathrm{SIH})$ is caused by spinal leakage of cerebrospinal fluid (CSF) and typically causes orthostatic headache which is relieved by lying in a recumbent position. We describe the case of a 44-year-old male suffering from orthostatic headaches accompanied by symptomatic cervical disc herniation, for which he had an anterior cervical discectomy and fusion (ACDF). Computerized tomography of the brain at the emergency department 1 week after this procedure showed bilateral subacute subdural hematomas. In retrospect, the positional headache had been present for 3 months prior to the ACDF, and magnetic resonance imaging of the cervical spine prior to the ACDF already showed signs of an extradural CSF collection indicating intracranial hypotension. This case highlights the possibility of $\mathrm{SIH}$ caused by a spinal dural leak due to cervical disc herniation.
\end{abstract}

(C) 2021 The Author(s)

Published by S. Karger AG, Basel

\begin{tabular}{ll}
\hline & Hille Koppen \\
Department of Neurology, LUMC/ Haga Hospital & \\
Els Borst-Eilersplein 275 \\
NL-2545 AA The Hague (The Netherlands) \\
h.koppen@lumc.nl
\end{tabular}




\section{Case Reports in Neurology}

\section{Introduction}

Spontaneous intracranial hypotension (SIH) occurs in 5 per 100,000 persons per year and is caused by spinal leakage of cerebrospinal fluid (CSF) [1]. The most common symptom of $\mathrm{SIH}$ is orthostatic headache, which is relieved by lying in a recumbent position, usually within 15-30 min. However, this positional component may be absent altogether [2]. Sometimes subdural effusions or hematomas complicate SIH [1].

The exact location of the CSF leak is often not easily identified. Leakage can be due to dural weakness surrounding nerve root sleeves, disc herniations causing small longitudinal slits in the ventral dura and, rarely, CSF venous fistulas [1,3-5].

In this report, we describe a case of bilateral subdural hematomas caused by SIH as a result of a probable dural defect caused by cervical disc herniation.

\section{Case Presentation}

A 44-year-old Caucasian male presented at our emergency department with severe stabbing-like headaches in the last 3 months. One week before presentation at our emergency department, an anterior cervical discectomy and fusion (ACDF) of C5-C6 and C6-C7 was performed for the treatment of cervical radicular symptoms caused by intervertebral disc herniation. He had no further medical history or relevant family history and had attributed the headache to the cervical disc herniation. Specifically, he could not recall any major head trauma. At first, his headache diminished for several days after the ACDF with postoperative painkillers and maintaining a supine position. However, similar stabbing headaches quickly returned, located in the neck and bifrontal, which worsened when standing. Additionally, he described nausea and symptoms of bradyphrenia. Physical examination showed no abnormalities.

Computerized tomography (CT) of the head made at presentation at the emergency department ( 1 week after the ACDF) showed bilateral subacute subdural hematomas with a moderate midline shift (Fig. 1a, b). In retrospect, the preoperative MRI (magnetic resonance imaging) showed signs of a spinal longitudinal extradural CSF collection indicating a spinal leak (Fig. 1c, d). Perioperatively, the neurosurgeon noticed dural leakage after removing a large right sided sequester at the level of $\mathrm{C} 5-\mathrm{C} 6$ without seeing a clear dural defect.

Based on the clinical and radiological findings, the diagnosis of SIH was made, and he was admitted to the hospital and treated conservatively with bed rest. Nonetheless, he developed progressive headaches accompanied by vomiting. After 5 days of bed rest, an evaluating CT was performed, revealing progression of the subdural hematoma on the left side after which $8 \mathrm{mg}$ of oral dexamethasone was initiated with tapering in 20 days. Follow-up imaging 5 days later showed unchanged hematomas. Since clinical symptoms improved, he was discharged from the hospital. At follow-up 1 month after his hospital stay, the headache almost completely resolved and he slowly started resuming his daily activities.

\section{Discussion}

This report describes a case of headache caused by bilateral subdural hematomas as a result of intracranial hypotension, possibly caused by a cervical spinal leak due to cervical disk

\section{Karger'=}




\section{Case Reports in Neurology}

Case Rep Neurol 2021;13:246-250

DOI: $10.1159 / 000511428$ www.karger.com/crn

Steenstraten et al.: Headache due to Bilateral Subacute Subdural Hematomas following Intracranial Hypotension Caused by Cervical Disc Herniation

herniation. The possible long-lasting SIH may have caused continuous traction and consequent tearing of bridging veins, causing the spontaneous subdural hematomas. The fact that this patient had no history of head trauma contributes to this hypothesis.

In this case, the neurosurgeon perioperatively confirmed cervical leakage of CSF, which raised the suspicion of SIH. He was not able to visualize the dural defect causing CSF leakage, probably because the dural defect was very small as is often seen in SIH caused by mechanical dural tears [3]. However, it cannot be completely ruled out that the operation itself caused the leakage, but as complaints of SIH were present months before the operation this seems unlikely. Also, in retrospect the cervical MRI showed a spinal longitudinal extradural CSF collection, pointing towards CSF leakage preceding the ACDF. These collections have a typical appearance and according to Farb et al. [6] are seen exclusively in patients with SIH with dural mechanical tears along the thecal sacs.

Therefore, although the spinal leakage was not visualized, the leak was probably caused by a spinal extradural pathology, in this case most probably the cervical disc herniation. One of the important etiologies for CSF leakage is ventral dural tears caused by calcified disk herniations with microspurs. In our case, calcifications or microspurs of the cervical disks could not be confirmed since no CT was performed prior to the procedure. This raises the question whether SIH and its dural defect could have been caused by cervical intervertebral disc herniation without signs of calcifications or microspurs. Fiechter et al. [7] described a case of SIH caused by disc herniation at the thoracolumbar junction, without any signs of calcification. Consequently in our case, even without a definite calcification, the cervical disc herniation constitutes a risk factor for causing ventral dural tears.

In our case, the headaches clinically improved over the following days after initiation of dexamethasone. Therefore, epidural blood patching, which carries a small risk of dural puncture and according worsening of CSF hypotension, was not performed [8]. According to Beck et al. [3], one of the major treatments of intractable SIH is removal of the discogenic cause of dural tears. They state that conservative treatment alone and even blood patching will be unsuccessful if the mechanical cause for the dural tear remains. Therefore, in our case, surgery probably contributed to the long-term treatment of the SIH.

Another important contribution to the diagnosis of SIH in this case was the presence of a spinal longitudinal extradural CSF collection. According to the third edition of the international classification of headache disorders, one of the important diagnostic criteria for SIH is the evidence of CSF leakage on imaging, including spinal imaging [9].

Therefore, one might pose if there is a high suspicion of SIH clinically, but cranial image is negative, additional spinal imaging might be helpful. Also, since microspurs are an important cause of spontaneous intracranial hypotension, spinal CT imaging might be a relevant addition to the diagnostic and therapeutic process.

\section{Statement of Ethics}

Informed consent was obtained from the patient in this case report for submission to the medical literature. The patient gave written informed consent to publish this case (including publication of images).

\section{Karger'=}




\section{Case Reports in Neurology}

\section{Conflict of Interest Statement}

The authors have no conflicts of interest to declare.

\section{Funding Sources}

The authors received no financial support for the research, authorship, and/or publication of this article.

\section{Author Contributions}

All three authors have contributed to the writing of this article. Iris C. Steenstraten drafted the manuscript and was involved in collection of the data, and gave final approval. Stephanie Mohamed contributed to acquisition of data, revising content and gave final approval. Hille Koppen designed and drafted the manuscript, interpreted the data, revised the data, gave final approval

\section{References}

1 Schievink WI. Spontaneous Spinal Cerebrospinal Fluid and ongoing investigations in this area. JAMA. 2006 May;295(19):2286-96. https://doi.org/10.1001/jama.295.19.2286.

2 Mokri B. Headaches caused by decreased intracranial pressure: diagnosis and management. Curr Opin Neurol. 2003 Jun;16(3):319-26.

3 Beck J, Ulrich CT, Fung C, Fichtner J, Seidel K, Fiechter M, et al. Diskogenic microspurs as a major cause of intractable spontaneous intracranial hypotension. Neurology. 2016 Sep;87(12):1220-6.

4 Merali Z, Witiw CD, Wang S, Phan N, Yang V. Spontaneous intracranial hypotension resulting in coma: Case report and review of the literature. Interdiscip Neurosurg. 2018 March;11:51-6. https://doi.org/10.1016/j.inat.2017.08.009.

5 Kranz PG, Malinzak MD, Amrhein TJ, Gray L. Update on the diagnosis and treatment of spontaneous intracranial hypotension. Curr Pain Headache Rep. 2017 Aug;21(8):37.

6 Farb RI, Nicholson PJ, Peng PW, Massicotte EM, Lay C, Krings T, et al. Spontaneous intracranial hypotension: A systematic imgaing approach for CSF leak localization and management based on MRI and digital substraction myelography. AJNR Am J Neuroradiol. 2019 Apr;40(4):745-53.

7 Fiechter M, Ott A, Beck J, Weyerbrock A, Fournier JY. Intradural non-calcified thoracic disc herniation causing spontaneous intracranial hypotension: a case report. BMC Surg. 2019 Jun;19(1):66.

8 Riley CA, Spiegel JE. Complications following large-volume epidural blood patches for postdural puncture headache. Lumbar subdural hematoma and arachnoiditis: initial cause or final effect? J Clin Anesth. 2009 Aug;21(5):355-9.

9 Headache Classification Committee of the International Headache Society (HIS). The International Classification of Headache Disorders, 3rd edition. Cephalalgia. 2018;38(1):1-211. 


\section{Case Reports in Neurology}

\begin{tabular}{l|l}
\hline Case Rep Neurol 2021;13:246-250 \\
\hline DOI: 10.1159/000511428 & $\begin{array}{l}\text { ○ 2021 The Author(s). Published by S. Karger AG, Basel } \\
\text { www.karger.com/crn }\end{array}$ \\
\hline
\end{tabular}

Steenstraten et al.: Headache due to Bilateral Subacute Subdural Hematomas following Intracranial Hypotension Caused by Cervical Disc Herniation
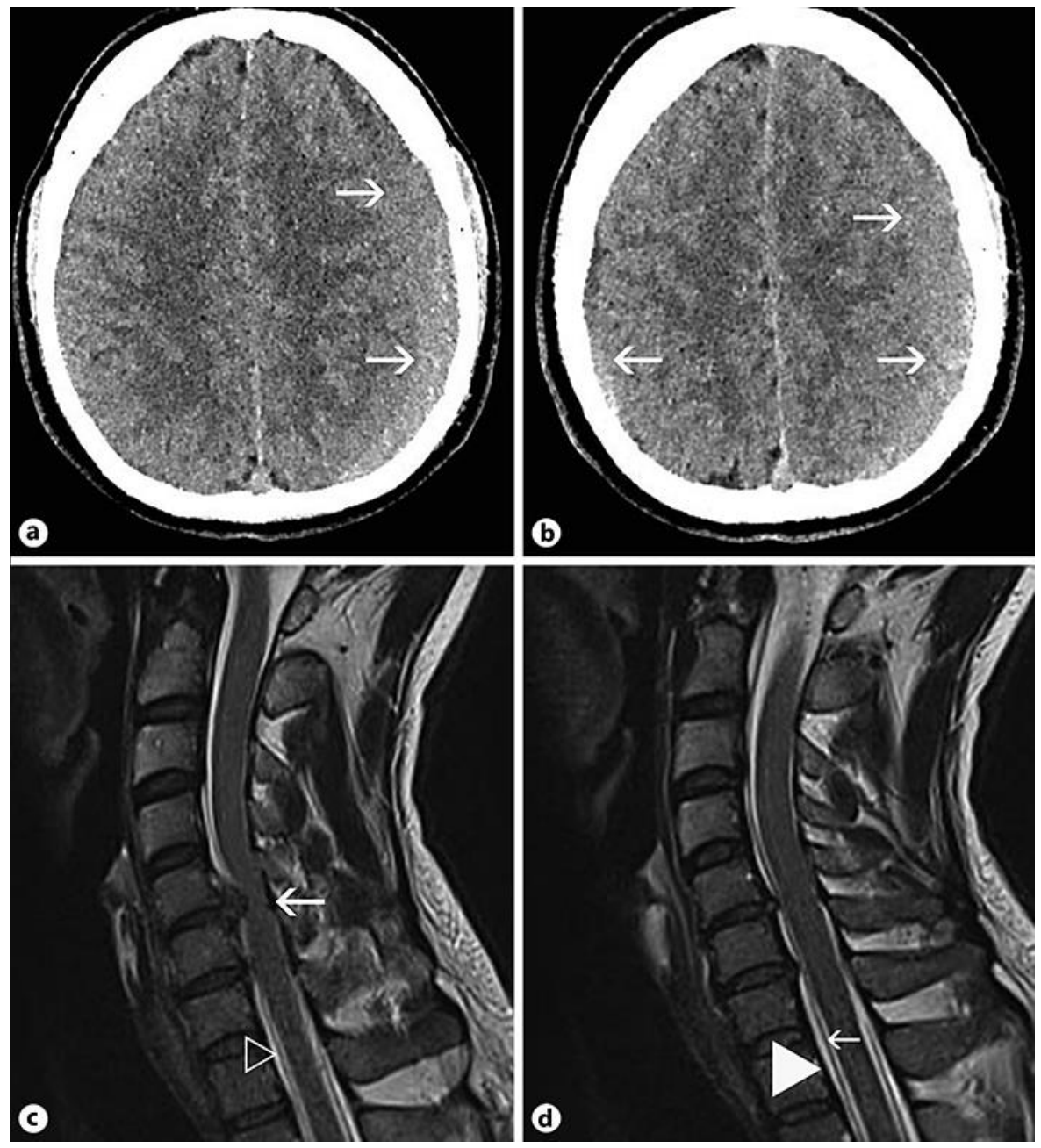

Fig. 1. a Computerized tomography of the head showing subacute subdural hematoma $12 \mathrm{~mm}$ over left convexity (arrows), midline shift not shown on this image. b Computerized tomography of the head showing subacute subdural hematoma $4 \mathrm{~mm}$ over right convexity as well (arrow). c Preoperative sagittal cervical magnetic resonance imaging showing disc herniation C5-C6 with dural displacement (arrow). Spinal longitudinal extradural CSF collection (arrowhead). d Preoperative sagittal cervical magnetic resonance imaging showing a spinal longitudinal extradural CSF collection (arrowhead). The arrow points at the dura. 